\title{
A case of corneal keloid: clinical, surgical, pathological, and ultrastructural characteristics
}

Jose Miguel Risco, Antonio Huaman, Sobhi R Antonios

\begin{abstract}
A 69-year-old patient developed a localised, whitish, elevated, corneal lesion with a smooth and glistening surface following trauma, without evidence of corneal perforation. Twelve months later, the lesion showed evidence of slow growth. An excisional biopsy was then performed. Histopathologically, the lesion was covered by non-keratinised squamous epithelium and was comprised of randomly oriented collagen fibres containing active fibroblasts. Blood vessels were noted deep in the lesion. Ultrastructurally, the cell population was formed by fibroblasts and myofibroblasts, similar to keloids of the skin. The clinical, pathological, and ultrastructural features of the corneal lesion are compatible with a corneal keloid.
\end{abstract}

(Br F Ophthalmol 1994; 78: 568-571)

Corneal keloids are rare lesions that can develop in cases of corneal insult. ${ }^{1-13}$ They can be present at any age and can appear as a single, solitary nodule or involve the entire corneal stroma. Keloids in general represent forms of hypertrophic scars produced by prolonged and excessive deposition of collagen and extend beyond the confines of the original trauma. ${ }^{14}$ is

Reported cases of corneal keloid are not common in the literature. ${ }^{1-13}$ Only one case was reported in a series of 302 cases of epibulbar tumours in children. ${ }^{16} \mathrm{We}$ report a case of an adult patient who developed a well localised corneal keloid following trauma. We initially examined the patient 5 months after the trauma, and observed the progression of the lesion over a 12-month period.

\section{Case report}

A 69-year-old patient was referred to King

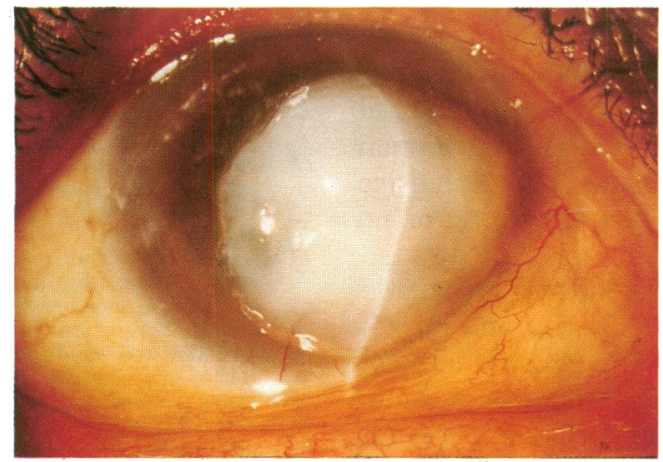

Figure 1 Appearance of the corneal keloid at the time of initial evaluation.
Khaled Eye Specialist Hospital and presented for the first time in February 1989 with a 5 month history of progressive, painless decrease in vision of his left eye following trauma with a fingernail. Details of the condition of the eye before the trauma as well as the extent and treatment of the initial injury were not available. After the initial injury, the patient noticed progressive 'opacification' of his left cornea. His ocular and medical history was non-contributory. There was no history of exuberant scar formation. Eye examination revealed a visual acuity of 20/200 in the right eye and hand motion in the left eye. Intraocular tensions were within normal limits. Scarring of the upper tarsal conjunctivae and superior limbic micropannus with Herbert's pits indicated old inactive trachoma in both eyes.

Mild climatic droplet keratopathy and an immature cataract accounted for the decreased vision in his right eye. Slit-lamp examination of the left cornea (Fig 1) revealed a whitish, smooth, glistening, and localised lesion, measuring approximately $9 \mathrm{~mm}$ in diameter, anterior to Bowman's layer. The remaining structures of the cornea were clear and the anterior chamber appeared to be of normal depth. Examination of the lens following mydriasis showed early cataractous changes. The rest of the examination was unremarkable. The patient was lost to follow up until January 1990 when it was noticed that the lesion on his left eye covered a larger area of the cornea (Fig 2). Shortly afterwards, the lesion was entirely removed by superficial keratectomy and was found to be easily dissected from the remaining corneal stroma (Fig 3). No evidence of a previous corneal perforation was noted, but the cornea was found to have superficial scarring. The postoperative course was unremarkable except for the cornea remaining mildly oedematous for about 6 months after surgery, without evidence of recurrence of a similar corneal lesion.

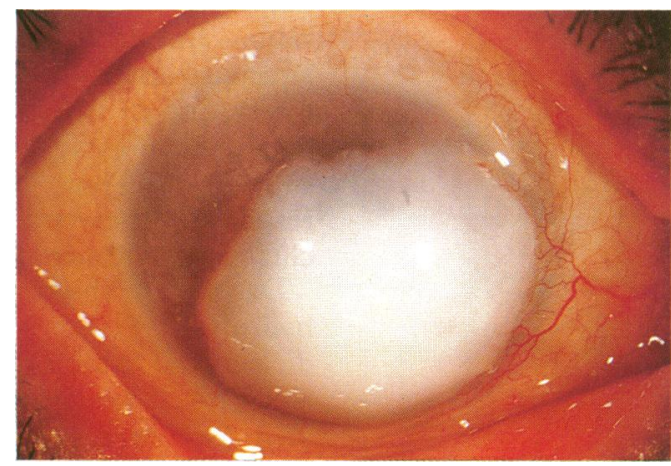

Figure 2 Aspect of the lesion 12 months after the initial examination. The lesion covers a larger area of the corneal surface. 


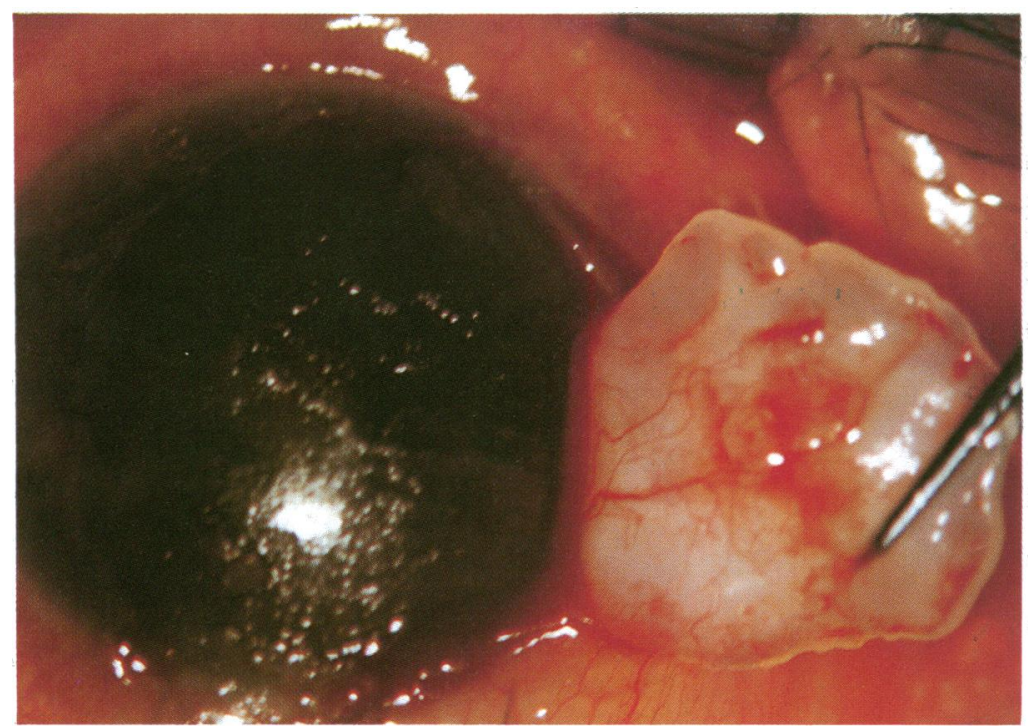

Figure 3 The corneal keloid at the time of surgical removal by a superficial keratectomy.

\section{Material and methods}

The surgical specimen was a circular, densely opaque piece of firm tissue measuring approximately $8 \mathrm{~mm}$ in diameter and up to $2.5 \mathrm{~mm}$ in thickness at the centre. It was initially fixed in neutral buffered formalin. The specimen was then bisected, and one half was processed for paraffin embedding, sectioned, and examined by light microscopy. The other half of the specimen was postfixed in $1 \%$ osmium tetroxide for 2 hours, and processed for electron microscopy.

\section{Results}

\section{PATHOLOGICAL EXAMINATION}

\section{Light microscopy}

Examination of the paraffin sections and thick plastic sections revealed fibrous tissue covered by non-keratinised squamous epithelium (Fig 4). Bowman's layer was absent, and both stroma and epithelium were oedematous. The lesion was composed of active fibroblasts and loosely arranged collagen. The basal part of the excised tissue stroma stained metachromatically with crystal violet. This basal, amyloid-like deposit

Figure 4 Light micrograph of the keloid. A nonkeratinised squamous epithelium covers the fibrous stroma $(\times 60)$. varied in thickness, but appeared in most instances as a continuous strip of about $3 \mu \mathrm{m}$ in thickness. The fibroblasts had moderately hyperchromatic, spindle-shaped nuclei, with occasional multinucleation, without loss of their benign character (Fig 5). Their cytoplasm was fibrillar and darkly acidophilic. Blood vessels of varying calibre coursed irregularly in the deep stroma. Sporadic spheroidal deposits consistent with climatic droplet degeneration (CDK) and increased elastic fibres were present along the posterior surface of the specimen. Congo red stains were negative.

\section{Electron microscopy}

The epithelium showed five to six layers of cells. The epithelium was separated from the underlying stroma by a basement membrane that exhibited frequent discontinuities.

The stroma was formed by collagen and by the cellular component, mostly fibroblasts. The collagen fibrils of the anterior half revealed ample interstitial spaces among them. The collagen fibrils of the posterior half of the stroma were relatively loose and randomly oriented (Fig 6 ). The collagen fibrils measured about $24 \mathrm{~nm}$ in diameter and revealed a distinct periodicity of $500 \mathrm{~nm}$. Amyloid-like deposits were seen in the form of more or less continuous ribbons of varying thickness demarcating the posterior edge of the keloid stroma. The fibrillary material of the amyloid-like deposits comprised an intricate meshwork of delicate filaments measuring about $10 \mathrm{~nm}$.

The fibroblasts were oval or, more commonly, slightly elongated. Characteristic features of most fibroblasts were fibrillar cytoplasm, well developed rough surfaced endoplasmic reticulum, numerous mitochondria, and one, sometimes two, prominent nucleoli (Fig 7). In many fibroblasts, the rough surfaced endoplasmic reticulum was markedly dilated and contained homogeneous, medium density material, occasionally intermingled with electron dense bodies or granules. Intracellular collagen was detected also in some fibroblasts in which microfibrils were situated within membrane bound tubular structures in the cytoplasm. Fibroblasts with dilated rough surfaced endoplasmic reticulum and glycogen storage were detected mostly in the anterior half of the stroma. Frequently seen were myofibroblasts (Fig 8) that incorporated subplasmalemmal tracts of filaments less than $4 \mathrm{~nm}$ in diameter and parallel to the long axis of the cell, with focal densities along their length. Moderate numbers of macrophage-like cells and few lymphocytes were also seen in the stroma.

\section{Discussion}

The term keloid has classically been used in the dermatologic literature to describe bulky scars at the site of injury. ${ }^{17}$ They are indistinguishable from hypertrophic scar by histological examination but clinically hypertrophic scars flatten spontaneously in the course of one to several years, while keloids persist and may even extend beyond the site of injury. ${ }^{1+}$ 


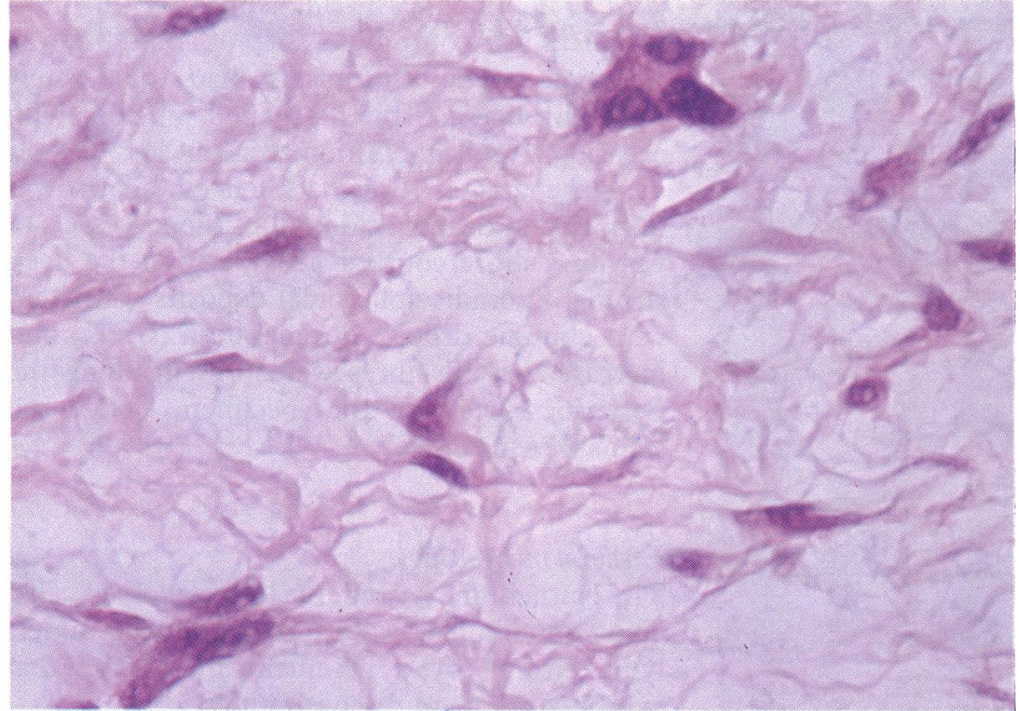

Figure 5 High power light micrograph shows the nature of the fibroblasts and their benign appearance $(\times 60)$.

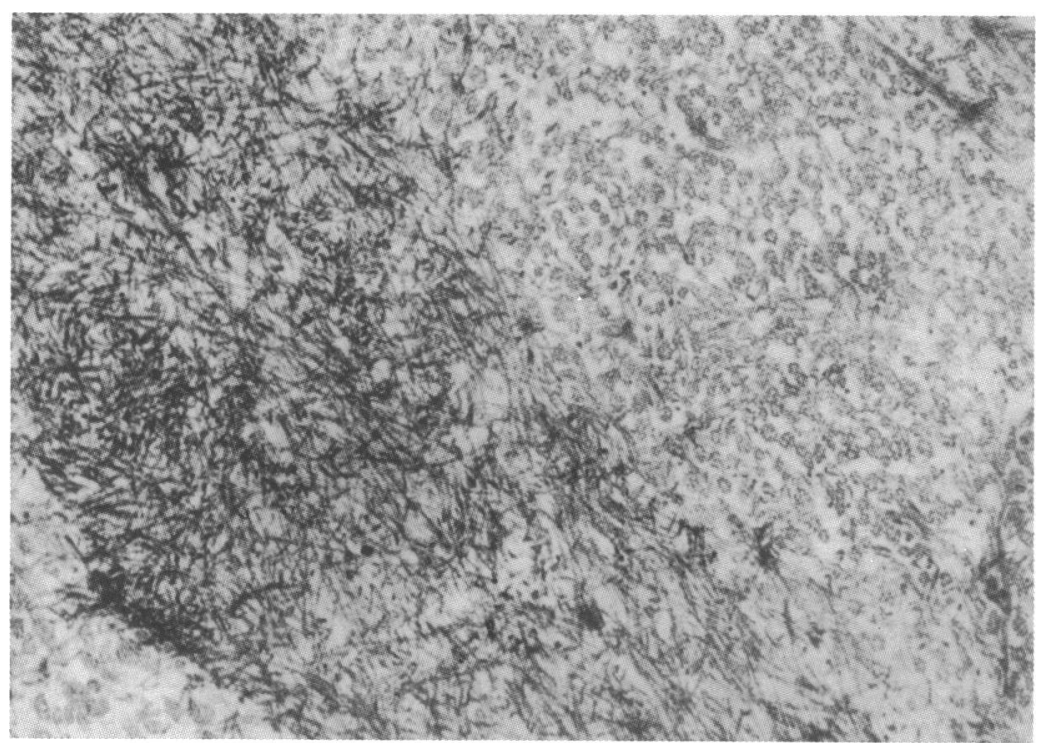

Figure 6 Electron micrograph of the collagen fibrils on the lesion. These fibrils are randomly oriented (magnification, $\times 18000$ )

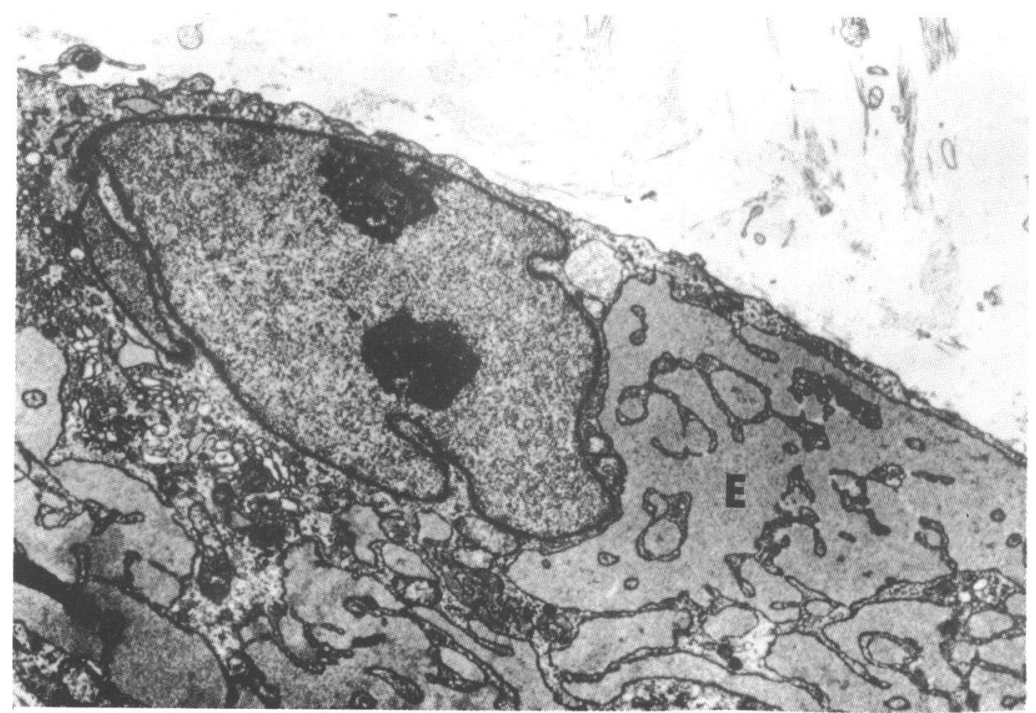

Figure 7 Electron micrograph of an active fibroblast with two nucleoli. The rough surfaced endoplasmic reticulum $(E)$ is markedly dilated (magnification, $\times 5400$ ).
The term 'corneal keloid' has been used previously in a wide range of clinical situations and has been introduced in a few isolated case reports. ${ }^{1-13}$ These reports include cases in which a corneal fibrous lesion develops after trauma, ${ }^{29}$ is present at birth,,$^{135612}$ in adult life ${ }^{19}$ after corneal perforation, ${ }^{511}$ following rubella keratopathy with perforation, ${ }^{4}$ following smallpox, ${ }^{7}$ in association with other developmental anomalies, ${ }^{12}$ in Lowe's syndrome, ${ }^{10}$ or as a result of a non-specific insult. ${ }^{1}$ In most of these cases, the diagnoses were established after histopathological examination of enucleated globes ${ }^{2-5711}$ and in specimens of penetrating keratoplasty. ${ }^{6} 912$

In contrast with our patient's lesion, posttraumatic corneal scars are not elevated lesions. Clinically, corneal keloids are described as whitish, fairly localised and poorly vascularised lesions, with a smooth and glistening surface. ${ }^{110}$ On several occasions they have been associated with corneal perforation, ${ }^{24}$ and it has been suggested that keloids may originate from iris tissue. O'Grady, 5 however, in a report of four cases, denies that iris incarceration is an important constituent in the formation of keloids.

Corneal keloids have been described in all age groups, from a congenital form, ${ }^{312}$ to those occurring in late adulthood. ${ }^{19} \mathrm{Smith}^{1}$ in 1940 collected data on 37 previously reported cases. Of these, 13 patients were less than 10 years of age at the time of presentation, and 27 of the 37 patients had a history of disease, injury, or surgery preceding the appearance of the corneal growth. Most of these corneal keloids were thought to have risen in staphylomatous corneas. Some of the congenital cases ${ }^{1-3}$ may represent staphylomatous corneas secondary to a previous keratopathy or possibly congenital glaucoma," and probably do not represent a true corneal keloid, but end stage postinflammatory healing with excessive scar formation. ${ }^{2}$ Spencer ${ }^{18}$ even doubts true keloids occur in the cornea.

It is pertinent that corneal keloid in children be differentiated from well defined conditions such as sclerocornea, corneal dermoid, Peter's anomaly, congenital hereditary endothelial dystrophy, congenital glaucoma, birth trauma, infections, and metabolic disease. ${ }^{12}$ In adults, the presence of a white, elevated, and localised lesion with a smooth and glistening surface that develops following trauma appears to be almost pathognomonic for a corneal keloid. In contrast, Salzmann's nodular degeneration occurs as a reactive process to a chronic keratitits of long duration. The nodular lesions in the corneal surface are small and tend to be multiple. Histopathologically the nodules reveal excessive secretions of basement-like material with collagen hyalinisation.

Our case differs from most cases previously reported and in our view, characterises the corneal keloid clinically, histopathologically, and surgically: historically, there is a well established traumatic event, there is a progressive growth of a white raised corneal opacity, there is a lesion populated by active fibroblasts and myofibroblasts, ${ }^{19}$ and a lesion completely resected with preservation of the corneal stroma. The presence of CDK and amyloid at the 


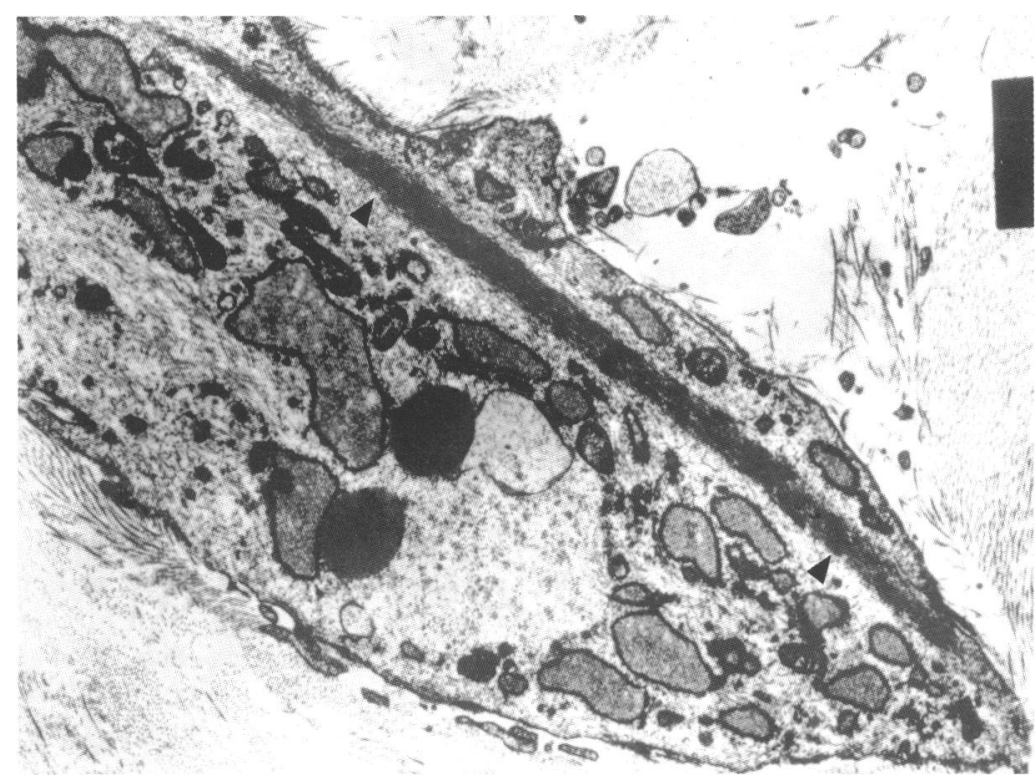

Figure 8 Electron micrograph of a myofibroblast showing characteristic subplasmalemmal tract of microfilaments with focal densities (arrowheads) (magnification, $\times 4800$ ).

interface are interpreted as pre-existing climatic manifestations. ${ }^{2021}$

The significance of myofibroblasts in wound healing has been elucidated ${ }^{22}$ : the myofibroblast actually represent a transformed fibroblast normally present in granulation tissue, that temporarily expresses smooth muscle phenotype (myofibrils, microtendons). It produces soft collagen type III and in time yields to conventional fibroblasts, producers of collagen type I that harden and retract the scar. In keloids and other forms of abnormal healing such as vitreoretinopathies, ${ }^{2324}$ anterior subcapsular cataracts, ${ }^{25}$ or nodular fasciitis, myofibroblasts persist longer than necessary and often dominate the cell population of the lesion. Eventually keloids collagenise slowly in the centre but do not retract. In our patient this abnormal, delayed healing process manifested itself by the bulky slow growth, the active fibroblasts and myofibroblasts, and the absence of harder collagen.

1 Smith HC. Keloid of the cornea. Trans Am Ophthalmol Soc 1940; 38: 519-38.

2 Fenton RH, Tridici TJ. Hypertrophic corneal scars (keloids). Surv Ophthalmol 1964; 9: 561-6.

3 Farkas TG, Znajda JP. Keloid of the cornea. Am $\mathcal{F}$ Ophthalmol 1968; 66: 319-23.

4 Frederique $G$, Howard $R$, Boniuk V. Corneal ulcers in rubella. Am f Ophthalmol 1969; 68: 996-1003.

5 O'Grady RB, Kirk HQ. Corneal keloids. Am $\mathcal{F}$ Ophthalmol 1972; 73: 206-13.

6 Brown SL. Corneal transplantation of the infant cornea. Trans Am Acad Ophthalmol Otolaryngol 1974; 78: OP461-6.

7 Shukla IM, Arora NP, Arora MM. Corneal keloid. Ind $\mathcal{f}$ Ophthalmol 1975; 23: 18-9.

8 Cotlier E. Discussion. In: Bergsma D, Bron AJ, Cotlier E, eds. The eye and inborn errors of metabolism. Birth defects. 1976; 12: 594.

9 Pouliquen Y, Dehrmy P, Chauvad M. Une lesion corneene bien particuliere; pannus hypertrophique. Bull Soc Ophtalmol Fr 1979; 79: 501-2.

10 Cibis GW, Tripathi RC, Tripathi BJ, Harris DJ. Corneal keloid in Lowe's syndrome. Arch Ophthalmol 1982; 100: 1795-9.

11 Lahav M, Cadet JC, Chirambo M, Rehani U, Ishii Y. Corneal keloids - a histopathologic study. Graefes Arch Clin Exp Ophthalmol 1982; 218: 256-61.

12 Weiner MJ, Albert DM. Congenital corneal keloid. Acta Ophthalmol 1989; 192 (suppl): 188-96.

13 Holbach LM, Font RL, Shivitz IA, Jones DB. Bilateral keloid-like myofibroblastic proliferation of the corneas in children. Ophthalmology 1990; 97: 1188-93.

14 Lever WF, Schaumburg-Lever G, eds. Tumors of fibrous tissue. In: Histopathology of the skin. 6th ed. Philadelphia: JB Lippincott, 1984: 604-5.

15 Linares HA, Kischer CW, Dobrkovskym M, Larson DL. The histiotypic organization of the hypertrophic scar in humans. histiotypic organization of the hyp

16 Elsas FJ, Green WR. Epibulbar tumors in childhood. Am $\mathcal{F}$ Ophthalmol 1975; 79: 1001-7.

17 Murray JC, Pollack SV, Pinell SR. Keloids: review. $A m \mathcal{F}$ Acad Derm 1981; 4: 461-70.

18 Spencer WH. Ophthalmic pathology. An atlas and textbook. Philadelphia: Saunders, 1985; 3: 289-92.

19 James WD, Besanceney CD, Odom RB. The ultrastructure of a keloid. F Am Acad Derm 1980; 3: 50-7.

20 Hidayat AA, Risco JM. Amyloidosis of corneal stroma in patients with trachoma. Ophthalmology 1989; 96: 1203-11.

21 Matta CS, Tabbara KF, Cameron JA, Hidayat AA, al-Rajhi AA. Climatic droplet keratopathy with corneal amyloidosis. Ophthalmology 1991; 98: 192-5.

22 Schurch W, Seemayer TA, Gabbiani G. The myofibroblast. In: Sternberg SS, ed. Histology for pathologists. 1st ed. Chapter 5. New York: Raven Press, 1992: 109-44.

23 Machemer R, van Horn D, Aaberg TM. Pigment epithelial proliferation in human retinal detachment with massive periretinal proliferation. Am $\mathcal{Y}$ Ophthalmol 1978; 85: 181-91.

24 Kampik A, Kenyon KR, Michels RG, Green WR, de la Cruz ZC. Epiretinal and vitreous membranes: comparative study of 56 cases. Arch Ophthalmol 1981; 99: 1445-54.

25 Novotny GE, Pau H. Myofibroblast-like cells in human anterior capsular cataracts. Virchows $\operatorname{Arch}(A)$ 1984; 404: 393-401. 